\title{
The excessive heatings in the Romanian Plain
}

\author{
Cătălina Mărculeț ${ }^{1}$ (iD) Cristina Dumitrică ${ }^{1}$ \\ ${ }^{1}$ Institute of Geography, Romanian Academy, 12 Dimitrie Racovita Street, 023993 Bucharest, Romania; \\ catalina.marculet@gmail.com (C.M.); geocrisro@yahoo.com (C.D.)
}

Received: 13 November 2019; Revised: 17 April 2020; Accepted: 25 April 2020; Published online: 29 April 2020

\begin{abstract}
The paper study the extremely hot days, with temperature $\geq 35^{\circ} \mathrm{C}$, on the basis of daily data of the maximum air temperature in the Romanian Plain - one of the territories in Romania with the highest excessive heatings. The excessively hot situations were analyzed in detail by: calculating the total number of extremely hot days gathered year by year and extracting the periods of different durations with such successive days, calculating the frequencies for the analyzed period, identifying the maximum duration intervals of each year and outlining the trends of their evolution. The extreme intensity of the heating is described by the manifestation data both in the air and on the ground. The extraordinary magnitude of the phenomenon was also highlighted by the MODIS satellite data, which indicated maximum temperatures above $50^{\circ} \mathrm{C}$, during the day and $35^{\circ} \mathrm{C}$ at night.
\end{abstract}

Key words: excessive heat, maximum temperatures, evolution trends, satellite data, Romanian Plain.

https://doi.org/10.47246/CEJGSD.2020.2.1.3

\section{| Full text |}

